\title{
Virtual Design of Human-Machine Cooperative Feeding Machine
}

\author{
Fuxiang $\mathrm{Xie}^{1}$, Mengmeng $\mathrm{Xu}^{2}$ and Xiaoxiao $\mathrm{Li}^{2}$
}

(1. School of Mechanical-electronic and Vehicle Engineering, Wei Fang University, Weifang,261061, China; 2. College of mechanical and Electronic Engineering, Shandong University of Science and Technology, Qingdao,266590, China)

\section{Keywords: Man-machine coordination; Cattle and sheep; Feeding; Design}

\begin{abstract}
In China, the mechanization of breeding industry has been mechanized from the beginning to the present complete set of equipment, and the series of products are becoming more and more perfect. In view of the obsolescence of cattle and sheep and other livestock breeding technology, a human-computer cooperative feeding machine was designed in this paper. The key parts of the four wheel chassis, steering system, transmission system and discharging mechanism were designed by using the 3D design technology and SOLIDWORKS software, and the geometric parameters and motion performance of the man-machine cooperative feeding machine were obtained. This machine was successfully implemented by man-machine cooperative feeding. It is suitable for the animal husbandry in retail. It has strong adaptability and was used for a variety of applications.
\end{abstract}

\section{Introduction}

China's animal husbandry industry has developed from small-scale peasant economy to small-scale farming households. Some breeding enterprises have achieved large-scale and standardized aquaculture. The old farming technology and low educational level result in limited acceptance of the introduction management concept, and the layout of small farmers can not be further optimized, these are mainly due to the fact that domestic farmers are mainly scattered in rural areas. The cultivation of retail households has also exacerbated the difficulty of health management and regulation ${ }^{[1 \sim 3]}$.

At present, there was still a big gap in the development of mechanization of animal husbandry between china and developed countries, but the mechanization of animal husbandry is becoming more and more perfect from the beginning of single mechanization to the complete set of equipment. There are two main types of markets for livestock machinery. First, it is suitable for small-scale, family farming and small ecological agriculture facilities, which is convenient for family operation and small scale operation. It is suitable for all kinds of materials processing, with comprehensive functions and relatively low price, which is urgently needed by farmers' friends. Second, The higher the technical level of the equipment was suitable for large and medium-sized farms. Based on most of the retail households are farmers, belonging to the side of the farm, the economic model of feeding domestic animal ${ }^{[4 \sim 5]}$.

In this paper, a man-machine cooperative feeding machine was designed for retail households in animal husbandry industry. It was suitable for livestock breeding and adaptability, and it was used for many purposes. It was applied to the rural economic mode, which can meet many aspects of needs, and has strong adaptability. It can not only reduce costs for farmers, but also effectively improve efficiency and save more time and space.

\section{Overall Structure and Working Principle}

The man-machine cooperative feeding machine was shown in Figure 1. The feeding machine was mainly composed of seat, steering wheel, speed box, drive shaft, engine, loading box, connecting rod mechanism, car body, tire and so on. The four wheel chassis was used as the carrier, with the corresponding structure. 


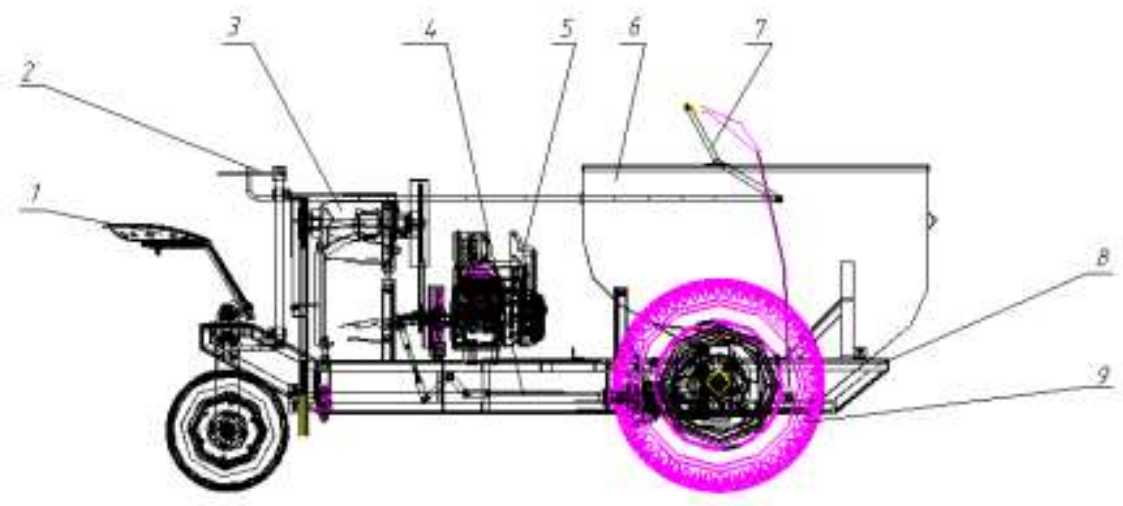

1. Chair 2. Steering wheel 3. Speed box 4. Transmission shaft 5. Engine 6. Loading box 7. Connecting rod mechanism 8 . car body 9 . tyre

Figure 1. Structure schematic diagram of a human-machine cooperative feeding machine

When the tank was loaded with appropriate amount of forage, start the engine. First ,the power passes through the two stage chain drive to adjust the speed. Next, the power was conveyed to the wheel axle through the shaft transmission, and then the wheel was turned to complete the dynamic operation. In the process of driving, We can increase the speed by increasing the throttle or reduce speed by stepping on the brakes according to the needs. When the material needs to be discharged, pull the rod on the left to open the floor, and then remove the material and finish the work. Brake system and transmission in different ways, the installation position of the system was in the transmission shaft section, using the belt to increase the friction force, the speed of the drive shaft is reduced, and the speed of the brake is reduced. In this case, the precision of the assembly of the shaft is required and the fixed end is stable, which will not affect the precision of the transmission. The pull rod system of material discharge adopts simple principle of connecting rod mechanism, artificial operation, clear structure and simple operation.

\section{Design of the Key Component}

Gear Transmission of Steering Gear. According to the design of the whole product of the feeding machine, the steering gear was designed reasonably. The completion of the steering instruction is driven by the meshing between the gears and then changes the direction of the operation. We need to use solid pinion and fan-shaped gear, because it requires small structural size, and gear was used to assist steering, so that not only saves part of the production material, but also enables the mechanism to simplify and generate unnecessary space ${ }^{[6 \sim 7]}$. The specific parameters were shown in Table 1. 
Table 1 Gear parameters

\begin{tabular}{ccc}
\hline & Active wheel & From the moving wheel \\
Dividing circle diameter $\mathrm{d}$ & $9(\mathrm{~mm})$ & $158(\mathrm{~mm})$ \\
Crown circle diameter $d_{a}$ & $13(\mathrm{~mm})$ & $161(\mathrm{~mm})$ \\
Root circle diameter $d_{f}$ & $7(\mathrm{~mm})$ & $156(\mathrm{~mm})$ \\
The number of teeth z & 9 & 124 \\
Pitch p & $9.7(\mathrm{~mm})$ & $7.6(\mathrm{~mm})$ \\
pressure angle a & $20^{\circ}$ & $20^{\circ}$ \\
Tooth width b & $20(\mathrm{~mm})$ & $9.5(\mathrm{~mm})$ \\
Center distance a & & $170(\mathrm{~mm})$ \\
\hline
\end{tabular}

The size of the drive wheel was very small, and the structure was solid. From the wheel is not a complete gear, The quarter quarter circle gear was selected for transmission steering, and the force was larger when it was driven. And this was not a fixed transmission form, but a bolt fixed on the rotation of the axle, in order to make the stability of the gear, The entity will be used here

The selection of materials can be obtained by look-up table. According to the actual operation needs, gear was required to have enough strength, hardness and excellent fatigue resistance, so that many times of mesh will not fail, so as to avoid affecting the operation or failure in driving, triggering accidents and other related problems, It also needs to have strong corrosion resistance because of exposure to the air. In summary, pinion material is selected as $40 \mathrm{Cr}$ (quenched and tempered), the hardness of the tooth surface is $280 \mathrm{HNS}$, the large gear material is 45 steel (quenched and tempered), and the hardness of the tooth surface is 240HBS.

According to the selection of the model and type of the feeding machine in this paper, the 7 grade precision can be obtained.

Chain Drive of Power Output. The chain transmission was in meshing with the power system, directly with the output shaft of the engine ${ }^{[6 \sim 7]}$, the specific parameters were shown in Table 2.

Table 2 Basic parameters of a sprocket

\begin{tabular}{|c|c|c|c|}
\hline \multicolumn{2}{|c|}{ Active wheel } & \multicolumn{2}{|c|}{ From the moving wheel } \\
\hline Pitch $\mathrm{p}$ & $12.7(\mathrm{~mm})$ & Pitch $\mathrm{p}$ & $12.7(\mathrm{~mm})$ \\
\hline Roller diameter $d_{1}$ & 7.92(mm) & Roller diameter $d_{1}$ & $7.92(\mathrm{~mm})$ \\
\hline The number of teeth & 59 & The number of teeth & 21 \\
\hline $\mathrm{z}$ & & $\mathrm{z}$ & \\
\hline Dividing circle & & Dividing circle & \\
\hline $\begin{array}{c}\text { diameter d } \\
\text { Crown circle }\end{array}$ & $246(\mathrm{~mm})$ & $\begin{array}{c}\text { diameter d } \\
\text { Crown circle }\end{array}$ & $87(\mathrm{~mm})$ \\
\hline diameter $d_{a}$ & $250(\mathrm{~mm})$ & diameter $d_{a}$ & $92(\mathrm{~mm})$ \\
\hline Root circle diameter & & Root circle diameter & \\
\hline$d_{f}$ & $238(\mathrm{~mm})$ & $d_{f}$ & $80(\mathrm{~mm})$ \\
\hline Maximum shaft & & Maximum shaft & \\
\hline flange diameter $d_{g}$ & $235(\mathrm{~mm})$ & flange diameter $d_{g}$ & $77(\mathrm{~mm})$ \\
\hline transmission ratio $\mathrm{i}$ & & 2.8 & \\
\hline Center distance a & & $307(\mathrm{~mm})$ & \\
\hline Chain number $L_{p}$ & & 102 & \\
\hline
\end{tabular}

The material used by the sprocket here was Q235, The driving wheel and the driven wheel are both solid, and the transmission distance is greatly shortened, and the stability of the drive was very 
strong. To sum up, the type of sprocket is 08A.1.102 GB/T 1243.2006.

Design of Shaft Parts. Axis rotation was not only widely used in mechanical equipment, but also has an irreplaceable role in other fields. This design uses different types of shaft products In the design of sprocket speed regulation, car body transmission and steering gear. A simple parameter description is made below.

The material of the shaft was selected according to the requirements, and 45 steel (tempering) was selected. The application range was wide and the performance is stable.

The minimum diameter of the axis can be calculated[8 9] by the formula (1):

$$
d_{\min }=A_{0} \sqrt[3]{\frac{p}{n}}
$$

$\mathrm{P}$ stands for transmission power, $\mathrm{kw} ; \mathrm{N}$ stands for the rotational speed of the axis, $\mathrm{r} / \mathrm{min}$.

$$
A_{0}=\sqrt[3]{\frac{9550000}{0.2\left[\tau_{T}\right]}}
$$

Choose $A_{0}=110$

The minimum diameter of each axis is obtained by the calculation of the data as follows, Sprocket drive shaft is $d_{1}=19.1 \mathrm{~mm}$; Car body drive shaft is $d_{2}=26.6 \mathrm{~mm}$; Steering shaft is $\mathrm{d}_{3}=23.8 \mathrm{~mm}$; Wheel shaft is $\mathrm{d}_{4}=19.1 \mathrm{~mm}$.

Design of Discharging Mechanism. Discharge is the last instruction to the feeding machine to complete the operation. It is also one of the important links in this design. The factors to be considered are also all-wave direction. The principle of material selection, the design of size and the mechanism, and so on, need to be carefully carried out.

Floor Discharge. The discharge plate was located at the bottom of the feeding machine, its material and size of the material plate should be different from the four sides of the carrier box, which was convenient for processing and manufacturing, because it carries the important part. The material is HT350 ${ }^{[10 \sim 11]}$. The middle of the floor was hollowed out, according to the type of feeding study and feeding forage, for cattle and other livestock, mostly feeding weeds or crop straw, in the cut will produce a portion of the slag in the bottom row of plate design into hollow state, in the process will jolt driving away the broken slag, in order to clean feed fodder. In the middle of a base plate and two hook nose, connected to the operating lever, to achieve the discharge freely; In addition, the three sections of hollow tubes at the upper end are matched with the axle of the car body to play the role of the loose leaf.

Operating Lever. The lever used for discharging material was designed on the left side of the driver, and the rod mechanism of the whole discharging device lies in this. Pulling the rod and combining skillfully the rod and the rotating pair can make the movement of the bottom plate move instantaneously, and complete the unloading.

Loading Box. The material handling box was the same as the front baseplate in the selection of materials. HT350 was adopted, and the structural design requirements were reasonably processed to integrate with the components, so that the assembly was convenient and so on ${ }^{[12]}$. The rear end face of the loading box was added with the triangle iron, which is used to reinforce the loading box, there was space at the bottom to install the discharge floor, and at the bottom, it has contact with the transmission shaft of the car body in order not to affect the transmission, it was designed to be a convex geometry .

Driving Parts. Driving parts include small parts, such as brake, oil, phase plate, and seat, etc ${ }^{[13]}$. This part of the design was simple, the right end on oil and brake were located in the driver and was located in front of the round bar. The steering wheel was designed into a simple tripod parallel frame structure; The seat was designed according to the comfort of the human body, with a small arc. 


\section{Summary}

A man-machine cooperative feeding machine was designed in the paper, mainly composed of seat, steering wheel, speed box, transmission shaft, engine, loading box, connecting rod mechanism, car body, tire and other components.

Based on SOLIDWORKS software, three dimensional design technology was used to design a human-computer cooperative feeding machine, and the motion parameters of the feeding machine were obtained.

On the basis of design analysis, the structure, material, type and cost of the key components of the man-machine cooperative feeding machine were obtained, which provides a theoretical basis for the production of the prototype.

\section{Acknowledgements}

This work was supported by Project of National Natural Science Foundation (No.51505337) and A Project of Shandong Province Higher Educational Science and Technology Program (J17KA150).

\section{References}

[1] Ding lina. Research on the supply and demand of Chinese meat sheep market and its future trend[D]. Beijing: China Agricultural University, 2014.

[2] Wu yanze, Xia jiqing, Kang defu, etc. Development of the unloader for the whole cow mixed $\operatorname{diet}[\mathrm{J}]$. Journal of Northeast Agricultural University, 2011,42(11):89-93.

[3] Yan shitao, Li fade, Song zhanhua,etc. Research status of fine feeding system for dairy cows[J]. Agricultural Mechanization Research, 2010,32(1):222-226.

[4] Li dianyou, Guo bengang. Aquaculture products processing technology question and answer. Beijing; Chemical Industry Press, 2015.

[5] Liu zhiqing. Introduction of major equipment for modern poultry establishments[J]. Aquaculture consultants.

[6] Chen guoding, $\mathrm{Wu}$ liyan, $\mathrm{Pu}$ lianggui. Mechanical design (Ninth Edition) Beijing: 2013.5(2014.12 Reprint). 2013,(09):241.

[7] Sun huan, Chen zuomo, Ge wenjie. Mechanical principle (8th Edition) Beijing: Higher Education Press, 2013.5(2014.12 Reprint).

[8]Wen bangchun. Manual of mechanical design (Fifth Edition). Beijing: Machinery Industry Press, 2015.

[9] Wen bangchun. Manual of mechanical design (Fifth Edition). The shaft and its connector. Beijing: Machinery Industry Press, 2015.

[10]Xie fan, Li jingbin, Kan za,etc. Design of self walking mutton feeding machine [J]. Agricultural Mechanization in Xinjiang, 2012,(4):10.11.

[11] Wang yuansun. A kind of poultry automatic feeding machine [J]. Poultry science, 2015,(06):56.

[12] Hohhot branch of Chinese Academy of Agricultural Mechanization Sciences. Traction vertical mixing feed car: China, CN201020599510.0[P].2011-8-3.

[13] Modern agricultural clothing Polytron Technologies Inc. A feeding system for feeding systems: China, CN200820109987.0[P].2009-8-26. 